\title{
The effect of telemedicine and social media on cancer patients' self-care: A systematic review
}

\author{
Fariba Sadat Agha Seyyed Esmaeil Amiri¹, Fatemeh Bohlouly ${ }^{1}$, Atefeh Khoshkangin ${ }^{1}$, Negin \\ Razmi $^{1}$, Kosar Ghaddaripouri ${ }^{1}$, Mohammad Reza Mazaheri Habibi ${ }^{2 *(D)}$
}

${ }^{1}$ Department of Health Information Technology, Varastegan Institute for Medical Sciences, Mashhad, Iran ${ }^{2}$ Department of Health Information Technology, Varastegan Institute for Medical Sciences, Mashhad, Iran

Article Info
$\begin{aligned} & \text { Article type: } \\ & \text { Review }\end{aligned}$

\section{Article History:}

Received: 2021-06-17

Accepted: 2021-09-13

Published: 2021-09-25

\section{* Corresponding author: \\ Mohammad Reza Mazaheri Habibi}

Department of Health Information Technology, Varastegan Institute for Medical Sciences, Mashhad, Iran

Email:MazaheriM@varastegan.ac.ir

\section{Keywords:}

Telemedicine

Social Networks

Self-Care

Cancer Patients
A B S T R A C T

Introduction: Cancer is an incurable disease that affects people regardless of age, sex, race and social, economic and cultural status. Most cancer patients are treated with a combination of treatments based on the type of tumor, the extent of the disease, and their physical condition. Selfmanagement programs empower people to deal with illness and improve their quality of life. Telemedicine in the form of mobile applications, websites and social networks is one of the effective tools to achieve this goal. The aim of this study was to investigate the impact of telemedicine and social media on self-care of cancer patients.

Material and Methods: English related articles were searched based on keywords in the title and abstract using PubMed and Scopus databases (from 1963 to December 2020). Keywords included telemedicine, social networking, self-care and m-health. Inclusion criteria included all studies published in English that examined the impact of telemedicine and social media on cancer patients' self-care. Review articles and non-intervention articles were excluded from the study.

Results: A total of 516 articles were selected by title. After reviewing the abstract, 80 articles remained to be reviewed. After evaluating the full text of these articles, 9 eligible articles were selected for final review. In terms of the type of cancer among these studies, prostate cancer had the largest share $(33 \%)$. In line with the main purpose of this study, in 7 articles $(77.8 \%)$ telemedicine had a significant positive effect on self-care of cancer patients and increased self-care. In one article (11.1\%) this effect was negative and reduced self-care. In 1 article (11.1\%) no effect was observed.

Conclusion: According to the results of the present study, it seems that webbased interventions and mobile health in most articles have been effective in increasing patients' self-care. However, due to the increasing number of cancers as well as the increasing use of telemedicine in the field of chronic diseases and cancer, the need for further studies is felt in this field.

Cite this paper as:

Agha Seyyed Esmaeil Amiri FS, Bohlouly F, Khoshkangin A, Razmi N, Ghaddaripouri K, Mazaheri Habibi MR. The effect of telemedicine and social media on cancer patients' self-care: A systematic review. Front Health Inform. 2021; 10: 92. DOI: $\underline{10.30699 / f h i . v 10 \mathrm{i} 1.316}$

\section{INTRODUCTION}

Cancer is one of the most feared diseases of the twentieth century and a major public health problem $[\underline{1}, \underline{2}]$. Cancer is one of the leading causes of death in the world with an outbreak of more than 10 million deaths annually. According to 2020 statistics, 19.3 million new cases of cancer have been diagnosed, the most common of which are breast (11.7\%), lung (11.4\%) and colon (10.0\%) cancers, respectively. The most common cancers in men are lung cancers $(14.3 \%)$, prostate $(14.1 \%)$ and colon $(10.6 \%)$ and the most common cancers in women include breast (24.5\%), colon $(9.4 \%)$ cancers. And lungs $(8.4 \%)$. Current epidemiological data show an increasing trend in cancer incidence and mortality over the next 40 years [ $\underline{3}-\underline{5}]$. The side effects of breast, prostate and colon cancers and their various treatments on the recovery of these cancers are very high and there is a possibility of cancer recurrence or subsequent 
cancers. After recovering, cancer patients experience symptoms such as pain, fatigue, distress, and anxiety, and if left unmanaged, it can affect their health and quality of life. Prevalence of self-management among cancer patients is one of their empowerment strategies [6, 7]. A review of studies shows that treatment teams provide patients with little information about the management of treatmentrelated side effects. Most people start cancer treatment on an outpatient basis and manage the side effects of the disease and treatment at home. As a result, increasing the ability and knowledge of patients in the field of self-care is essential for the experience of safe and quality care at home []. In a study conducted by Sanne et al., it was found that selfmanagement can be one of the ways to treat and thus save more people with this disease [9] . Today, the world's technology is the most widespread and its ubiquity and various features have led to its use in the field of health under the name of mHealth $[\underline{8}, \underline{10}]$. The role of mHealth in cancer care has evolved with the rapid development of digital technology [10, 11]. When telemedicine is used for palliative care, the results indicate an improvement in symptom management as well as patient and family satisfaction $[\underline{12}, \underline{13}]$. Also, the results of examining the information of people who have used health selfmanagement programs are positive and show their ability to promote health. Due to the widespread use of social networks, they can also be used for this purpose [14]. In addition, the increasing population load in medical centers, especially in densely populated areas, poses barriers to treatment for many patients. Telemedicine makes it possible to reduce these barriers by increasing skills in specialization and minimizing travel burden [15]. Among these applications, WhatsApp plays a prominent role in health education interventions [16]. Telemedicine, on the other hand, involves the provision of health care services through communication technologies. Therefore, telemedicine technology and social media can be used for self-care of cancer patients []․ The aim of this study was to investigate the impact of telemedicine and social media on self-care of cancer patients.

\section{MATERIAL AND METHODS}

English language articles were searched based on keywords in the title and abstract using the PubMed and Scopus databases from 1963 to 2020 (Fig 1).

The search strategy used is as follows:

Analysis of the list of articles found completed the search. In other words, article list analysis was performed to increase search accuracy. The titles and abstracts of the articles were reviewed separately by two browsers and the differences and shortcomings were resolved by the third researcher.
Inclusion criteria included all studies published in English that examined the impact of telemedicine and social media on cancer patients' self-care. Review and non-intervention articles were excluded from this study.

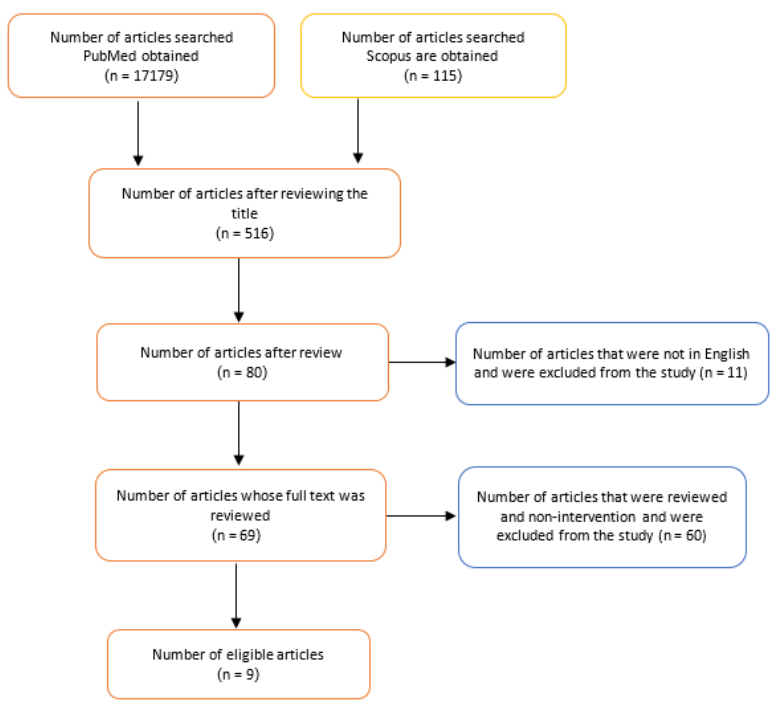

Fig 1: PRISMA flowchart

\section{RESULTS}

The search of the PubMed and Scopus databases yielded 17,294 articles. After a preliminary review of the title and abstract, 80 articles were eligible for full text evaluation. By reviewing the full text of the articles, 71 articles were deleted and 9 articles were selected for more detailed analysis. The characteristics of these studies are reported in Table 1.

According to Table 1, out of 9 studies, prostate cancer had the largest share in terms of type of cancer (33\%). In terms of study type, most cases were related to RCT studies (77.8\%). These 9 articles were published between 2014 and 2020, with the highest frequency belonging to 2019 articles (33\%).

In line with the main purpose of this study, in 7 articles (77.8\%) telemedicine had a significant positive effect on self-care of cancer patients and increased self-care. In one article (11.1\%) this effect was negative and reduced self-care and in one article (11.1\%) no effect was observed.

\section{DISCUSSION}

Due to the lack of systematic review articles on the impact of telemedicine and social media on the selfcare of cancer patients, the present study investigated the role of these technologies in the selfcare of cancer patients. In summary, out of 9 reviewed articles, in 7 articles (77.8\%) telemedicine had a significant positive effect on the self-care of cancer patients and increased self-care. In one article 
$(11.1 \%)$ this effect was negative and reduced selfcare and in one article (11.1\%) no effect was observed.

Frankland et al. showed that their self-management and remote monitoring program has a positive effect in solving prostate cancer problems in men [17]. In another study by Ekstedt et al., the ePATH selfmanagement program showed that people living with prostate cancer, their families, and health care professionals have access to a digital tool. Establishes a link between the patient and health care providers and supports self-care and empowerment during the care and treatment period. This study also increased knowledge about how to support patients in self-care and the feeling of involvement in self-care [18]. In line with the main objectives of this study, Papadopoulou et al. reported in their study that self-efficacy in patients undergoing chemotherapy is a good center for educational and behavioral interventions and is recognized as an effective tool on patient-reported outcomes [19].

Table 1: Characteristics of the studies reviewed

\begin{tabular}{|c|c|c|c|c|c|c|c|}
\hline Ref & $\begin{array}{l}\text { Author } \\
\text { name }\end{array}$ & $\begin{array}{l}\text { Country } \\
\text { of study }\end{array}$ & $\begin{array}{l}\text { Year of } \\
\text { study }\end{array}$ & $\begin{array}{l}\text { Study } \\
\text { Design }\end{array}$ & $\begin{array}{l}\text { Sample } \\
\text { size }\end{array}$ & $\begin{array}{l}\text { Type of } \\
\text { cancer }\end{array}$ & Outcome: Self-care \\
\hline [] & Rico & Brazil & 2020 & RCT & $\begin{array}{l}118 \\
\text { patients }\end{array}$ & - & $\begin{array}{l}\text { SMS-based intervention has the } \\
\text { ability to manage side effects. }\end{array}$ \\
\hline [17] & Frankland & UK & 2019 & RCT & $\begin{array}{l}627 \\
\text { patients }\end{array}$ & prostate & Effective in self-care \\
\hline [18] & Ekstedt & Sweden & 2019 & RCT & $\begin{array}{l}242 \\
\text { patients }\end{array}$ & prostate & $\begin{array}{l}\text { Increase the feeling of participation in } \\
\text { self-care }\end{array}$ \\
\hline$[\underline{20}]$ & Knoerl & $\begin{array}{l}\text { United } \\
\text { States }\end{array}$ & 2019 & RCT & $\begin{array}{l}752 \\
\text { patients }\end{array}$ & - & $\begin{array}{l}\text { There was no significant difference } \\
\text { between the self-care of the } \\
\text { intervention and control groups }\end{array}$ \\
\hline$[\underline{21}]$ & Giesler & Germany & 2017 & RCT & $\begin{array}{l}205 \\
\text { patients }\end{array}$ & Colorectal & Reduce self-care \\
\hline [24] & Zargarzadeh & Iran & 2018 & $\begin{array}{l}\text { Mixed } \\
\text { method }\end{array}$ & $\begin{array}{l}19 \\
\text { apps }\end{array}$ & prostate & Effective in self-care \\
\hline$[\underline{25}]$ & Xie & China & 2020 & RCT & $\begin{array}{l}86 \\
\text { patients }\end{array}$ & $\begin{array}{l}\text { gastroint } \\
\text { estinal }\end{array}$ & $\begin{array}{l}\text { Beneficial effects of self-care } \\
\text { education }\end{array}$ \\
\hline
\end{tabular}

Xie et al. showed that self-care education has beneficial effects on the quality of life of patients with gastrointestinal cancer undergoing chemotherapy [25]. In addition, text messaging may be a tool to support the management of side effects in patients receiving chemotherapy []. Self-care education can also be considered as a complementary method during chemotherapy in patients with gastrointestinal cancer [25]. It seems that providing education to patients can be effective in increasing self-management and thus improving their quality of life.

However, in Knoerl et al.'s study, participants 'adherence to physicians' recommendations or the use of additional self-management strategies did not improve compared with controls [을. Giesler et al. also stated that the results of this study do not support the hypothesis that the website under study may increase the effectiveness of coping with cancer or patient competencies such as self-regulation or control of emotional distress. The reason could be the characteristics of the website, its use by participants or methodological reasons [21]. In contrast, a study by Borosund et al. showed that a web-based tool could significantly reduce depression in cancer patients and could be promising. It was also stated that providing support through the web or telemedicine as part of regular care can be a powerful tool to help patients in self-management of their disease [23]. In line with the objectives of this study, Zargarzadeh et al. stated that the mobile application can also help in the self-care of patients in need of prostate cancer treatment [24].

On the other hand, a study by Cnossen et al. showed patient satisfaction with online self-care education. It should be noted that satisfaction with this program was associated with the level of education and health literacy skills and its use was possible for patients who had access to the Internet [22]. It seems that the level of education and having the necessary facilities to use online self-care programs is related to their level of satisfaction with these programs.

One of the strengths of the present study was the no limitation to a specific type of cancer and covered all types of cancers. The limitation of this study was investigating English language studies lonely. The reason was the greater number of articles in English than in other languages. 
In general, telemedicine seems to increase self-care in cancer patients. Digital tools also provide a platform for patient support. These programs are a powerful tool in self-care during the course of treatment and management of disease side effects. In addition, patients' satisfaction with online self-management training programs is high. It also seems that the characteristics of the website and the psychological characteristics of the patients who use these websites can affect the degree of self-regulation or control of their emotional distress.

\section{CONCLUSION}

Telemedicine and social media play a significant role in the self-care of cancer patients. Self-care education increases the quality of life of cancer patients and can be used as a complementary method during treatment, especially chemotherapy. Self-care programs for cancer patients provide a digital tool that enhances patient empowerment.

\section{AUTHOR'S CONTRIBUTION}

All authors contributed to the literature review, design, data collection and analysis, drafting the manuscript, read and approved the final manuscript.

\section{CONFLICTS OF INTEREST}

The authors declare no conflicts of interest regarding the publication of this study.

\section{FINANCIAL DISCLOSURE}

No financial interests related to the material of this manuscript have been declared.

\section{REFERENCES}

1. Siegel RL, Miller KD, Jemal A. Cancer statistics: 2020. A Cancer Journal for Clinicians. 2020; 70(1): 7-30.

2. Roy PS, Saikia BJ. Cancer and cure: A critical analysis. Indian J Cancer. 2016; 53(3): 441-2. PMID: 28244479 DOI: 10.4103/0019-509X.200658 [PubMed]

3. Sung H, Ferlay J, Siegel RL, Laversanne M, Soerjomataram I, Jemal A, et al. Global Cancer Statistics 2020: GLOBOCAN Estimates of Incidence and Mortality Worldwide for 36 Cancers in 185 Countries. CA Cancer J Clin. 2021; 71(3): 209-49. PMID: 33538338 DOI: 10.3322/caac.21660 [PubMed]

4. Torre LA, Siegel RL, Ward EM, Jemal A. Global cancer incidence and mortality rates and trends: An update. Cancer Epidemiol Biomarkers Prev. 2016; 25(1): 1627. PMID: 26667886 DOI: 10.1158/1055-9965.EPI15-0578 [PubMed]

5. Zaimy MA, Saffarzadeh N, Mohammadi A, Pourghadamyari H, Izadi P, Sarli A, et al. New methods in the diagnosis of cancer and gene therapy of cancer based on nanoparticles. Cancer Gene Ther. 2017; 24(6): 233-43. PMID: 28574057 DOI: 10.1038/cgt.2017.16 [PubMed]

6. O'Malley DM, Davis SN, Devine KA, Sullivan B, Bator A, Clemow L, et al. Development and usability testing of the e-EXCELS tool to guide cancer survivorship follow-up care. Psychooncology. 2020; 29(1): 123-31. PMID: 31626397 DOI: 10.1002/pon.5222 [PubMed]

7. Akin S, Kas Guner C. Investigation of the relationship among fatigue, self-efficacy and quality of life during chemotherapy in patients with breast, lung or gastrointestinal cancer. Eur J Cancer Care (Engl). 2019; 28(1): e12898. PMID: 30039883 DOI: 10.1111/ecc.12898 [PubMed]

8. Rico TM, Dos Santos Machado K, Fernandes VP, Madruga SW, Santin MM, Petrarca CR, et al. Use of text messaging (SMS) for the management of side effects in cancer patients undergoing chemotherapy treatment: A randomized controlled trial. J Med Syst. 2020; 44(11): 193. PMID: 32996027 DOI: 10.1007/s10916-020-01663-x [PubMed]

9. van den Berg SW, Gielissen MF, Custers JA, van der Graaf WT, Ottevanger PB, Prins JB. BREATH: webbased self-management for psychological adjustment after primary breast cancer--Results of a multicenter randomized controlled trial. J Clin Oncol. 2015; 33(25): 2763-71. PMID: 26169621 DOI: 10.1200/JCO.2013.54.9386 [PubMed]

10. Tarricone R, Cucciniello M, Armeni P, Petracca F, Desouza KC, Hall LK, et al. Mobile health divide between clinicians and patients in cancer care: Results from a cross-sectional international survey. JMIR Mhealth Uhealth. 2019; 7(9): e13584. PMID: 31493318 DOI: 10.2196/13584 [PubMed]

11. Chan RJ, Howell D, Lustberg MB, Mustian K, Koczwara $\mathrm{B}, \mathrm{Ng} \mathrm{CC}$, et al. Advances and future directions in the use of mobile health in supportive cancer care: Proceedings of the 2019 MASCC annual meeting symposium. Support Care Cancer. 2020; 28(9): 405967. PMID: 32405966 DOI: 10.1007/s00520-02005513-x [PubMed]

12. Worster B, Swartz K. Telemedicine and palliative care: An increasing role in supportive oncology. Curr Oncol Rep. 2017; 19(6): 37. PMID: 28417310 DOI: 10.1007/s11912-017-0600-y [PubMed]

13. Stotts MJ, Grischkan JA, Khungar V. Improving cirrhosis care: The potential for telemedicine and mobile health technologies. World J Gastroenterol. 2019; 25(29): 3849-56. PMID: 31413523 DOI: 10.3748/wjg.v25.i29.3849 [PubMed]

14. O'Neill P, Shandro B, Poullis A. Patient perspectives on social-media-delivered telemedicine for inflammatory bowel disease. Future Healthc J. 2020; 7(3): 241-4. PMID: 33094237 DOI: 10.7861/fhj.20200094 [PubMed]

15. Shalowitz DI, Moore CJ. Telemedicine and gynecologic cancer care. Obstet Gynecol Clin North Am. 2020; 47(2): 271-85. PMID: 32451018 DOI: 


\subsection{6/j.ogc.2020.02.003 [PubMed]}

16. Pereira AA, Destro JR, Bernuci MP, Garcia LF, Lucena TF. Effects of a WhatsApp-delivered education intervention to enhance breast cancer knowledge in women: Mixed-methods study. JMIR Mhealth Uhealth. 2020; 8(7): e17430. PMID: 32706726 DOI: 10.2196/17430 [PubMed]

17. Frankland J, Brodie H, Cooke D, Foster C, Foster R, Gage $\mathrm{H}$, et al. Follow-up care after treatment for prostate cancer: evaluation of a supported selfmanagement and remote surveillance programme. BMC Cancer. 2019; 19(1): 368. PMID: 31014282 DOI: 10.1186/s12885-019-5561-0 [PubMed]

18. Ekstedt M, Schildmeijer K, Wennerberg C, Nilsson L, Wannheden C, Hellström A. Enhanced patient activation in cancer care transitions: Protocol for a randomized controlled trial of a tailored electronic health intervention for men with prostate cancer. JMIR Res Protoc. 2019; 8(3): e11625. PMID: 30900999 DOI: $10.2196 / 11625$ [PubMed]

19. Papadopoulou C, Kotronoulas G, Schneider A, Miller MI, McBride J, Polly Z, et al. Patient-reported selfefficacy, anxiety, and health-related quality of life during chemotherapy: Results from a longitudinal study. Oncol Nurs Forum. 2017; 44(1): 127-36. PMID: 27991612 DOI: 10.1188/17.0NF.127-136 [ [PubMed]

20. Knoerl R, Hong F, Blonquist T, Berry D. Impact of electronic self-assessment and self-care technology on adherence to clinician recommendations and selfmanagement activity for cancer treatment-related symptoms: Secondary analysis of a randomized controlled trial. JMIR Cancer. 2019; 5(1): e11395.
PMID: 30622093 DOI: 10.2196/11395 [PubMed]

21. Giesler JM, Keller B, Repke T, Leonhart R, Weis J, Muckelbauer R, et al. Effect of a website that presents patients' experiences on self-efficacy and patient competence of colorectal cancer patients: Web-based randomized controlled trial. J Med Internet Res. 2017; 19(10): e334. PMID: 29030329 DOI: 10.2196/jmir.7639 [PubMed]

22. Cnossen IC, van Uden-Kraan CF, Eerenstein SE, Jansen F, Witte BI, Lacko M, et al. An online self-care education program to support patients after total laryngectomy: Feasibility and satisfaction. Support Care Cancer. 2016; 24(3): 1261-8. PMID: 26306518 DOI: $10.1007 / \mathrm{s} 00520-015-2896-1$ [PubMed]

23. Børøsund E, Cvancarova M, Moore SM, Ekstedt M, Ruland CM. Comparing effects in regular practice of ecommunication and web-based self-management support among breast cancer patients: Preliminary results from a randomized controlled trial. J Med Internet Res. 2014; 16(12): e295. PMID: 25525672 DOI: 10.2196/jmir.3348 [ PubMed]

24. Zargarzadeh P, Ehteshami A, Mohammadi-Sichani M. A contribution into developing a model for prostate cancer self-care mobile application. Med Arch. 2018; 72(5): 344-7. PMID: 30524166 DOI: 10.5455/medarh.2018.72.344-347 [마Med]

25. Xie J, Zhu T, Lu Q, Xu X, Cai Y, Xu Z. The effects of addon self-care education on quality of life and fatigue in gastrointestinal cancer patients undergoing chemotherapy. BMC Complement Med Ther. 2020; 20(1): 15. PMID: 32020863 DOI: 10.1186/s12906019-2800-5 [PubMed] 